\title{
Study of the microstructure of a collapsible soil flooded with $\mathrm{NaCl}$ saline
}

\author{
Ouassila Bahloul ${ }^{1, a}$ Khelifa Abbeche ${ }^{1}$ and Azeddine Bahloul ${ }^{2}$ \\ ${ }^{1}$ Department of Civil Engineering, University of Batna, Algeria \\ ${ }^{2}$ CGI Technical Services, 1612 Wedding Way Redding, California, 96003 USA
}

\begin{abstract}
Collapsible soils are unsaturated soils which may undergo inter-granular rearrangement with abrupt and significant volume reduction after wetting. The large settlement resulting from the soil collapse pushed for deep studies of these types of soils. The experimental study consists to illustrate the influence of the salt concentration, compaction energy and moisture content on the change of microstructural characteristics of the reconstituted soil and reduction of the collapse potential.
\end{abstract}

\section{Introduction}

The collapse of soils is at the origin of several engineering problems, such as excessive settlement of large civil construction and public works projects works in many regions of the world. The collapse can occur in the case of a natural soil (aeolian deposits, alluvial deposits or residual soils) or compacted soils (embankments compacted on the dry side of the Proctor optimum curve). Generally, collapsible soils are defined as metastable soils that contain voids within their structures composed often grains ranging from silt to fine sand [1].The present study aims to illustrate that it is possible to decrease the potential of collapse of a soil reconstituted in the laboratory to an acceptable level. Also, to study the effect of a salt solution (sodium chloride $\mathrm{NaCl}$ ) at various concentrations as well as the effect of energy of compaction on the potential of collapse of the same soil, while varying the vertical stress. We present a set of evaluations with scanning electron microscopy (SEM) of samples of untreated reconstituted and on samples treated by various salts, to correlate the macroscopic evaluations to the results obtained at the microscopic level obtained by oedometer tests, and to discuss the effects of the addition of salts on the microstructure and the physical properties of the reconstituted.

\section{Materials, Equipment and Test}

The reconstituted soil sample is composed of $80 \%$ of sand and $20 \%$ of kaolin. The application of various criteria of collapse, as indicated by [2-3], show that this material is collapsible.

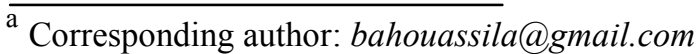
abbechekhelifa@hotmai.com
}

\subsection{Characteristics of Materials}

The sand used in the sample reconstitution comes from the Liwa River located in the region of Biskra, Algeria screened on the $2 \mathrm{~mm}$ sieve; and its geotechnical characteristics are given in the Table 1. The kaolin soil used in this study is extracted from Debbagh area of Guelma, Algeria.

Table 1. Geotechnical characteristics of Materials

\begin{tabular}{|c|c|}
\hline Materials & Characteristics \\
\hline Sand & $\begin{array}{l}\text { Sand equivalent } \mathrm{SE}=87 \% \\
\text { Coefficient of uniformity } \mathrm{Cu}=3.91 \\
\text { Coefficient of curvature } \mathrm{Cc}=0.95 \\
\text { Grain size distribution }(0.08-2 \mathrm{~mm}) \\
\text { with } 3.03 \% \text { of particles }<80 \mu \mathrm{m} .\end{array}$ \\
\hline Kaolin & $\begin{array}{l}\mathrm{D}<80 \mu \mathrm{m} \\
\text { Liquid limit } \mathrm{LL}=67(\%) \\
\text { Plastic limit } \mathrm{PL}=39(\%) \\
\text { Specific Gravity } \mathrm{GS}=2.4\end{array}$ \\
\hline $\begin{array}{l}\text { Reconstituted } \\
\text { soil } \\
(80 \% \text { sand } \\
+20 \% \text { kaolin })\end{array}$ & $\begin{array}{l}\text { Coefficient of uniformity } \mathrm{Cu}=5.13 \\
\text { Coefficient of curvature } \mathrm{Cc}=1.07 \\
\text { Liquid limit } \mathrm{LL}=28(\%) \\
\text { Plastic limit } \mathrm{PL}=16(\%) \\
\text { Specific gravity } \mathrm{GS}=2.65 \\
\text { Maximum dry density }\left(\mathrm{g} / \mathrm{cm}^{3}\right) \gamma_{\mathrm{d}}=1.93 \\
\text { Optimal water content } \mathrm{w}_{\mathrm{opt}}=10(\%)\end{array}$ \\
\hline
\end{tabular}

In order to obtain samples with different degrees of compaction, those samples are moistened at different water contents, then they are subject to different compaction energies (20, 40 and 60 drops) [2], The samples thus prepared were tested using an oedometer by saturating them with solutions at different salt concentrations. Generally, work treating the effect of 
salts on the microstructural characteristics and hydraulic behaviour of clay materials use concentrations up to 1 $\mathrm{mol} / \mathrm{L}[4,5,6]$. The salt solution used for the soil treatment is sodium chloride $(\mathrm{NaCl})$ with various concentrations $(0.5,1.0,1.5$ and $2 \mathrm{~mol} / \mathrm{L})$.

\subsection{Characteristics of Consistency of the reconstituted Soil}

The literature revealed that a soil is likely to collapse if at least one of the following criteria is verified: activity of soil $\left(A_{c}<1\right)$, liquid index $\left(I_{1}<0\right)$, plasticity index $(P I \leq 20)$, consistence index $\left(I_{c}>1\right)$ and manageability index $\left(I_{w} \leq 1\right)$ [3-7], The results presented in Table 2 show that the soil of our study is likely to collapse, and that four of the five criteria mentioned above are checked, which confirms the results of [8],

Table 2. Characteristics of consistency of the reconstituted soil

\begin{tabular}{|l|c|c|c|c|c|}
\hline $\mathrm{W}_{0}{ }^{*}$ & $\mathrm{Ac}$ & $\mathrm{PI}$ & $\mathrm{I}_{1}$ & $\mathrm{I}_{\mathrm{c}}$ & $\mathrm{I}_{\mathrm{w}}$ \\
\hline 2 & & & -1.17 & 2.17 & 0.16 \\
\cline { 1 - 4 } & \multirow{3}{*}{2.60} & 12 & -0.67 & 2.00 & 0.33 \\
\cline { 1 - 4 } & & & -0.83 & 1.83 & 1.50 \\
\hline
\end{tabular}

\subsection{Physico-Chemical Characteristics of the Reconstituted Soil}

It was found that the Cation Exchange Capacity (CEC) of the sample is low according to Table 3 with a saturated adsorption complex. The CEC is essentially determined by the nature and content of the clay fraction, which in our case consists of kaolin mixed with smectites impurities. The $\mathrm{pH}$ indicates that the material is alkaline and the electrical conductivity (EC) is low.

Table 3. Characteristics of consistency of the reconstituted soil

\begin{tabular}{|lll|lll|}
\hline \multicolumn{3}{|c|}{ Adsorption complex } & \multicolumn{3}{c|}{ Solution soil } \\
\hline & & $\mathrm{pH}$ & 7.36 & \\
& & $\mathrm{EC}$ & 1.2 & $\mathrm{~ms} / \mathrm{cm}$ \\
$\mathrm{Ca}^{++}$ & 0.21 & $\mathrm{meq} / 100 \mathrm{~g}$ & $\mathrm{CO}_{3} \mathrm{H}^{-}$ & 3.88 & $\mathrm{meq} / 1$ \\
$\mathrm{Mg}^{++}$ & 0.10 & $\mathrm{meq} / 100 \mathrm{~g}$ & $\mathrm{SO}_{4}^{--}$ & 2.5 & $\mathrm{meq} / 1$ \\
$\mathrm{~K}^{+}$ & 0.13 & $\mathrm{meq} / 100 \mathrm{~g}$ & $\mathrm{Cl}^{-}$ & 5.52 & $\mathrm{meq} / 1$ \\
$\mathrm{Na}^{+}$ & 2.07 & $\mathrm{meq} / 100 \mathrm{~g}$ & $\mathrm{Ca}^{++}$ & 4.50 & $\mathrm{meq} / 1$ \\
$\mathrm{CEC}$ & 2.51 & $\mathrm{meq} / 100 \mathrm{~g}$ & $\mathrm{Mg}^{++}$ & 3.70 & $\mathrm{meq} / 1$ \\
& & & $\mathrm{Na}^{+}$ & 3.00 & $\mathrm{meq} / 1$ \\
& & $\mathrm{~K}^{+}$ & 0.80 & $\mathrm{meq} / 1$ \\
\hline
\end{tabular}

\section{Oedometer results}

The results obtained illustrate the collapse potential $C_{p}$ varies from 0.98 to $12.40 \%$ for initial water content $\mathrm{w}_{0}=2 \%$, from 0.82 to $10.64 \%$ for initial water content $\mathrm{w}_{0}=4 \%$; and from 0.66 to $8.79 \%$ for an initial water content $\mathrm{w}_{0}=6 \%$. After treatment, we constate a substantial reduction of potential of collapse $\mathrm{C}_{\mathrm{p}}$ for al soils treated with sodium chloride $(\mathrm{NaCl})$ with various concentrations. The maximum potential of collapse $C_{p}$ is obtained of vertical stress $400 \mathrm{kPa}$. Figure 1 show that the potential $\mathrm{C}_{\mathrm{p}}$ decreases almost linearly when the water content or the compaction energy increase, for vertical stress of 400 $\mathrm{kPa}$. It should be noted that the potential of collapse $\mathrm{C}_{\mathrm{p}}$ decreases when initial water content or initial compaction energy increase. That is attributed to the reduction of the suction forces when the initial water content increases and denser structure when the energy increases.

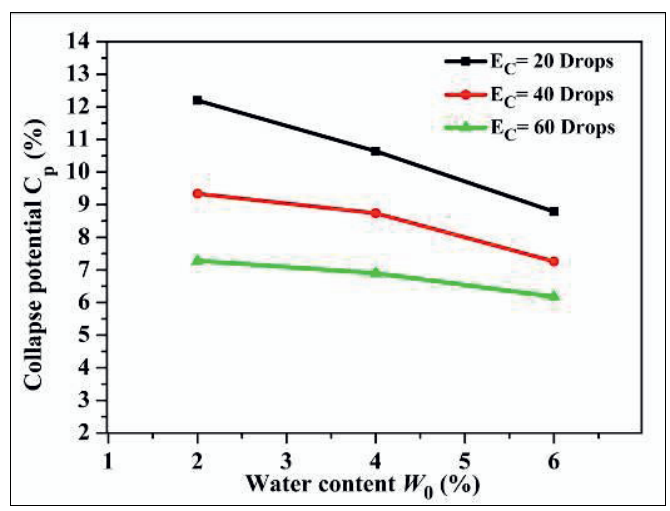

Figure 1. Variation of the collapse potential $\mathrm{Cp}$ with respect to water content for untreated soil at a vertical stress of $400 \mathrm{KPa}$

\section{Observations under the Scanning Electron Microscope (S.E.M.)}

\subsection{Quartz Structure: Case of the Untreated Soil}

In the case of the untreated soil under compacting force 20 drops, we notice a loose contact between kaolinite crystallites and the quartz crystals (Figure 2). Kaolinite crystallites do not present any preferential orientation compared to the quartzose skeleton (Figure 3). This type of microstructure was reported by various authors $[9,10$, $11]$.

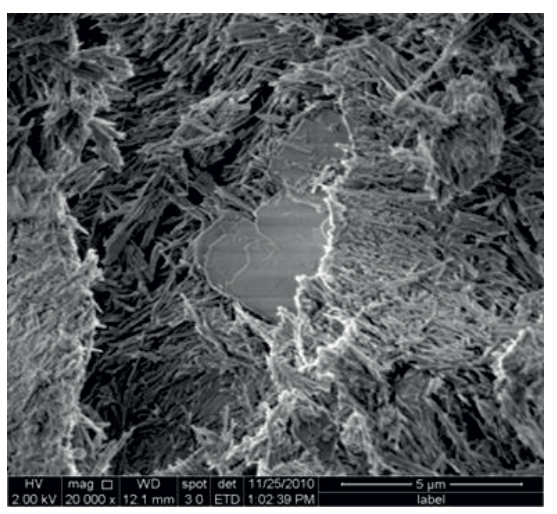

Figure 2. Electron photomicrograph of reconstituted untreated soil sample (20 drops). 
Figure 3 shows that the material compacted with 40 drops is a little more packed than the sample subjected to a compacting force of 20 drops. Quartz crystals are coated with crystallites of kaolinite with more coverage than the sample that has undergone slight compaction energy (20 drops).

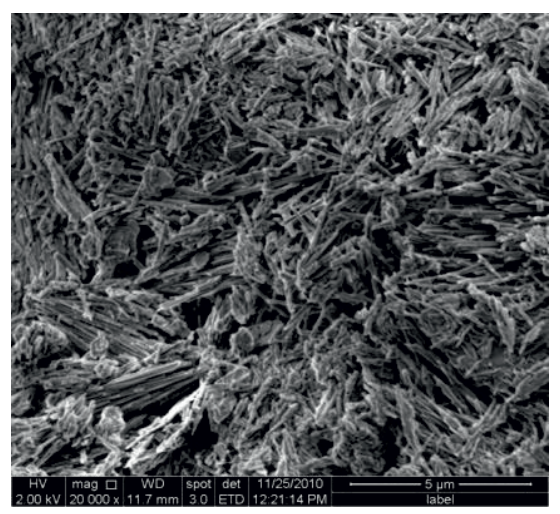

Figure 3. Electron photomicrograph of reconstituted untreated soil sample (40 drops).

Figure 4 shows that the material compacted under the effect of a force of 60 drops has a denser coating than the previous samples compacted under 20 and 40 drops and has a low porosity. The crystallites of kaolinite without define boundaries cover the quartz crystals.

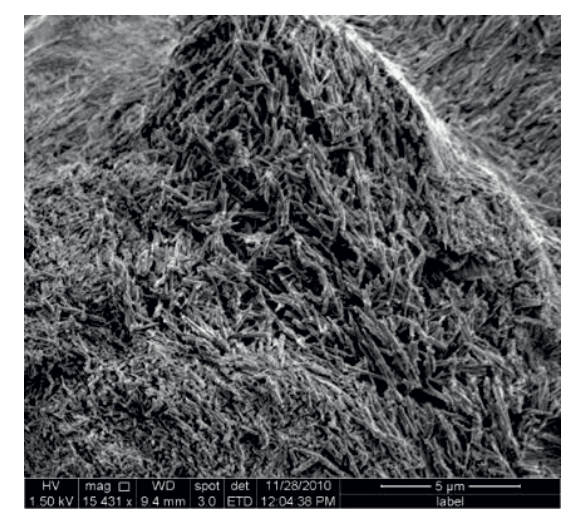

Figure 4. Electron photomicrograph of reconstituted untreated soil sample (60 drops).

\subsection{Relation Salt-Fine particles: Case of $\mathrm{NaCl}$}

The treated sample presents cubic $\mathrm{NaCl}$ crystals (halite) relatively crystallized, coated with clay in the form of sticks or rods in mixture with a smectite and quartz crystals. A figure 5 and 6 indicates that a space exists between the clay fraction and the $\mathrm{NaCl}$ crystals with certain fracture porosity. X-rays analysis reveals a higher concentration of silicon ( $\mathrm{Si}$ ) versus aluminum (Al) due to the presence quartz and kaolin, which reveals the presence of three-layer clay beside the Kaolin. Halite is highlighted in the X-ray analysis by peaks of sodium $(\mathrm{Na})$ and chlorine $(\mathrm{Cl})$ (Figure 7).

The mechanical behavior of the reconstituted sample in the presence of soluble salts is attributed to the effects of the salts on the interstitial solution of the soil and the modification of the exchange complex ionic structure of the clay.

First of all, because of the increase in the ionic force of the solution of the soil, the diffuse double layer of clays is compressed, which results in a flocculation of the material and its stabilization compared to reference material (untreated soil). As for the effects of the adsorbed cations, their nature plays an important part in the physical and mechanical behavior of the cohesive material. The alkaline cation monovalent $\mathrm{Na}+$ compresses the diffuse double layer particularly when the solution of the soil presents a weak ionic force; thus supports with high water content the swelling and the dispersion of the clay particles [12].That has as a consequence in obstructing the pores of the material and its densification.

An important characteristic of the electrostatic forces is their instability in connection with the water content. Indeed, when the material is very wet, the distance between the particles increases and the electrostatic force decreases. At the extreme, the electrostatic forces disappear; thus, a repulsion of the elementary particles occurs. Therefore, the sodic materials (rich in adsorbed sodium) with low hydric potential retain water

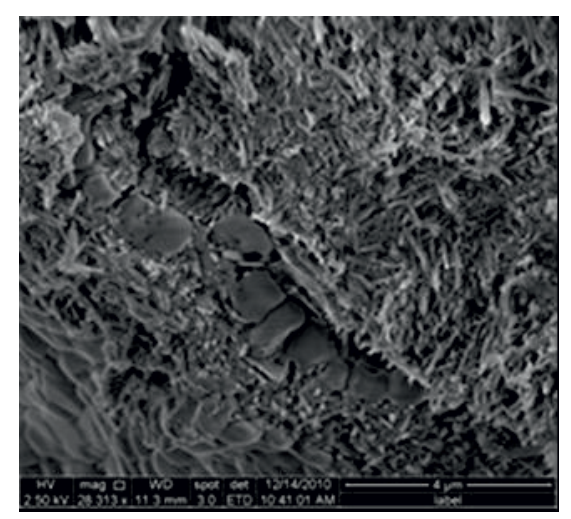

Figure 5. Electron photomicrograph of treated soil by $\mathrm{NaCl}$ Smectite and quartz crystals.

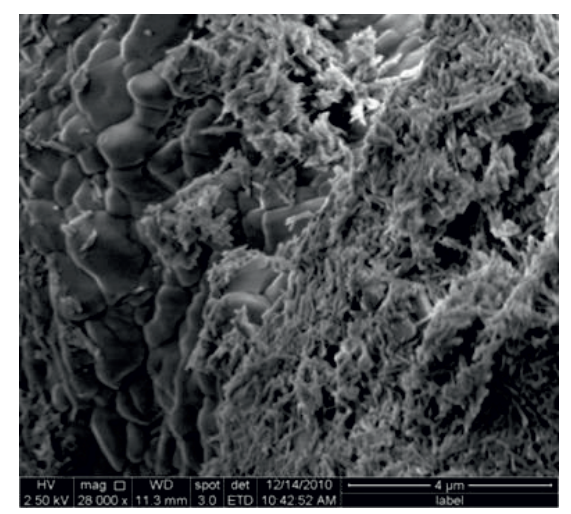

Figure 6. Electron photomicrograph of treated soil by $\mathrm{NaCl}$ quartz crystals, fracture porosity. 


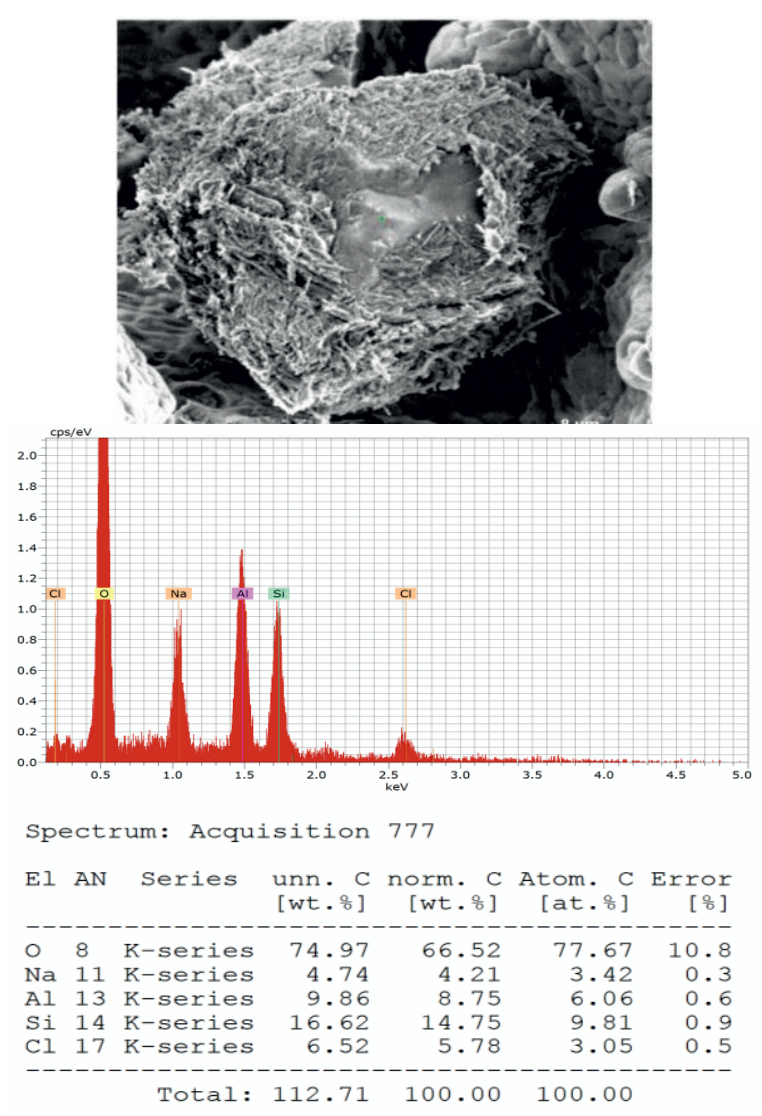

Figure 7. X-ray output spectrum of treated soil by $\mathrm{NaCl}$.

\section{Conclusions}

The collapse of soils is a very complex phenomenon involving a large number of intrinsic and environmental parameters. It is mainly due to the rearrangement of the soil particles after flooding.

The main observations of this study are:

- The collapse potential is reduced with increase of initial water content and increase of energy of compaction;

- $\quad$ The treatment by salt $(\mathrm{NaCl})$ reduced the collapse potential and subsequently the damage associated with it to structures;

- The study of the microstructure by the SEM showed that the reconstituted soil is characterized by a porous structure based on loose skeleton of grains with $80 \%$ of sand (quartz) and a clayey fraction (20\% of kaolin with a small proportion of smectite) is unevenly distributed

- The crystalo-chemistry of its constituents; and on the other hand to the physico-chemical properties in relation with the composition of pore solution and the ion structure of the exchange complex.

- $\quad$ Effect of the cation $\mathrm{Na}^{+}$has a dispersing effect on the colloids but being also translated by a dense and compact material. The cation favors the formation of a stable material.

\section{Acknowledgements}

We would like to thank the members of CGI Technical Services for their contributions to this study.

\section{References}

1. J.H. Dudley., JSMF. Div, ASCE 96:925-947. (1970)

2. K. Abbeche, M. Laouar, F. Messaoud., S.G.M, XXXII 2:.3-21, (2010)

3. AJ. Lutenegger, RT. Saber., G.T.J, 11, 3:173-178, (1988)

4. D. Tessier, J. Berrier, S.S, (1979)

5. A. Halitim., Thesis, University Rennes : 383, (1985)

6. K. Abbeche, O. Bahloul, T. Ayadat, A. Bahloul., Experimental and Applied Modeling of Unsaturated Soils, Proceedings of Geoshanghai, June 3-5, Shanghai, Chine.doi:10 1061/41103(396)10, (2010)

7. T. Ayadat, A. Hanna., G.T.J, 30 (2007)

8. K. Abbeche, M. Laouar, F. Messaoud., S.G.M, XXXII 2::3-21, (2010)

9. K. Rollins, M. Wayne, G. Rogers., J.G.E, 120, (1994)

10. O. B, Grabowska., B.I.A.E.G, Krefeld. (1975)

11. EC. Lawton, R J. Fragaszi, H. James., J.G, ASCE, 155,9: 1252-1267, (1989)

12. A. Halitim, M. Robert, D. Tessier, R. Prost., Agronomie, 4 :451-459. (1984) 